\title{
FUNDOS SOBERANOS DE INVESTIMENTO E IMUNIDADE DE JURISDIÇÃO
}

\author{
Ely Caetano Xavier Junior \\ SOVEREIGN WEALTH FUNDS AND IMMUNITY FROM JURISDICTION
}

\section{RESUMO}

OS FUNDOS SOBERANOS DE INVESTIMENTO TÊM AUMENTADO O VOLUME FINANCEIRO E DIVERSIFICADO AS ESTRATÉGIAS DE OPERAÇÃO NO MERCADO FINANCEIRO GLOBAL. ESSA ATUAÇÃO TEM SUSCITADO DIVERSOS QUESTIONAMENTOS JURÍDICOS, QUE SE ESTENDEM DESDE A FORMA SOCIETÁRIA ESCOLHIDA PARA A OPERAÇÃO DOS FUNDOS ATÉ A MOTIVAÇÃO POLÍTICA DOS INVESTIMENTOS REALIZADOS. O FENÔMENO ECONÔMICO É, ENTRETANTO, ACOMPANHADO POR UM RELATIVO ATRASO REGULATÓRIO, QUE SE LIMITA A INSTRUMENTOS DE SOFT LAW, EM INICIATIVAS CAPITANEADAS PELO FUNDO Monetário InTERnACIONAL E PELA ORgANIZAÇÃo PARA COOPERAÇÃO E DeSEnVOLVIMENTO ECONÔMICO. UMA DAS DIVERSAS QUESTÕES CONTROVERSAS SOBRE OS FUNDOS SOBERANOS DE INVESTIMENTO É A POSSIBILIDADE DE INVOCAÇÃO DO BENEFÍCIO DA IMUNIDADE DE JURISDIÇÃO. A FRAGMENTAÇÃO DO TRATAMENTO LEGISLATIVO E JURISPRUDENCIAL CONCEDIDO A EMPRESAS ESTATAIS E BANCOS CENTRAIS SUGERE RESPOSTAS CONTRADITÓRIAS QUANTO AOS FUNDOS SOBERANOS DE INVESTIMENTO. ESTANDO LONGE DE ENCONTRAR RESPOSTAS CONCLUSIVAS, É POSSÍVEL APENAS EXTRAIR ALGUNS PARÂMETROS PARA A ANÁLISE DOS CASOS CONCRETOS.

\section{PALAVRAS-CHAVE}

FUNDOS SOBERANOS DE INVESTIMENTO; IMUNIDADE DE JURISDIÇĀO; DIREITO INTERNACIONAL ECONÔMICO; REGULAÇÃO; SOBERANIA.

\begin{abstract}
SOVEREIGN WEALTH FUNDS HAVE INCREASED THEIR TRADING VOLUME AND DIVERSIFIED THEIR STRATEGIES TO OPERATE IN GLOBAL FINANCIAL MARKETS. THIS ACTIVITY HAS RAISED MANY LEGAL QUESTIONS, WHICH ENCOMPASS NOT ONLY THE CHOSEN LEGAL CORPORATE FORM BUT ALSO THE POLITICAL MOTIVATION UNDERNEATH THE INVESTMENT. THIS ECONOMIC PHENOMENON IS HOWEVER FOLLOWED BY A RELATIVE REGULATORY DELAY, WHICH IS LIMITED TO SOFT LAW INSTRUMENTS RESULTING FROM INITIATIVES SPEARHEADED BY THE INTERNATIONAL MONETARY Fund AND THE ORGANIZATION FOR ECONOMIC COOPERATION AND DEVELOPMENT. ONE OF THE SEVERAL CONTROVERSIAL ISSUES ABOUT SOVEREIGN WEALTH FUNDS IS THE POSSIBILITY OF INVOKING THE BENEFIT OF IMMUNITY FROM JURISDICTION. THE FRAGMENTATION OF LEGISLATIVE AND JUDICIAL TREATMENT GIVEN TO STATE-OWNED ENTERPRISES AND CENTRAL BANKS SUGGESTS INCONSISTENT ANSWERS REGARDING SOVEREIGN WEALTH FUNDS. BEING FAR FROM ACHIEVING CONCLUSIVE ANSWERS, IT IS ONLY POSSIBLE TO IDENTIFY SOME PARAMETERS FOR THE ANALYSIS OF SPECIFIC CASES.

\section{KEYWORDS}

SOVEREIGN WEALTH FUNDS; IMMUNITY FROM JURISDICTION INTERNATIONAL ECONOMIC LAW; REGULATION; SOVEREIGNTY.
\end{abstract}

\section{INTRODUÇÃO}

Em 1953, com o acúmulo das reservas de capital oriundas da indústria petrolífera, o Kuwait decidiu constituir o Kuwait Investment Office como parte de sua estratégia para reduzir a dependência econômica da exploração do recurso natural. O Kuwait Investment Office tinha como objetivo gerenciar os investimentos daquele Estado no 
exterior e não atraiu atenção internacional até 1987, quando adquiriu 20\% da British Petroleum. As autoridades britânicas, entretanto, pressionaram os investidores estrangeiros a alienar metade da participação originariamente adquirida (BADIAN; HARRINGTON, 2009, p. 146).

A iniciativa histórica do Kuwait foi acompanhada por outros países que buscavam alternativas para a utilização das reservas internacionais resultantes da intensificação das exportações de commodities, do aumento do preço do barril de petróleo, do superávit de arrecadação fiscal e de outros movimentos da economia globalizada (CARVALHO, 2009, p. 12).

As economias emergentes da Ásia inauguraram, mais recentemente, um novo ciclo de criação e fortalecimento de fundos soberanos de investimento. Em 2007, a China decidiu criar a China Investment Coorporation para investir o capital resultante do aumento das exportações. No ano seguinte, a Rússia inaugurou o National Welfare Fund em consequência do fortalecimento de sua economia (DAS, 2009, p. 87-88). Na Europa, ainda em 2008, a França inaugurou o Fonds Stratégique d'Investissement, sendo acompanhada, em 2011, pelo Fondo Strategico Italiano da Itália, ambos com objetivos de fortalecimento estratégico da atuação econômica daqueles países. ${ }^{1}$

Em dezembro de 2008, a Lei n. 11.887 criou o Fundo Soberano Brasileiro, vinculado ao Ministério da Fazenda, "com as finalidades de promover investimentos em ativos no Brasil e no exterior, formar poupança pública, mitigar os efeitos dos ciclos econômicos e fomentar projetos de interesse estratégico do País localizado no exterior”. Do ponto de vista estrutural, o Fundo Soberano Brasileiro é controlado por um Conselho Deliberativo composto pelo Ministro da Fazenda, o Ministro do Planejamento e o Presidente do Banco Central do Brasil. A criação do fundo soberano pelo Brasil foi vista por muitos críticos como um movimento apenas político. Nesse sentido é a análise de Backer (2010, p. 46):

Despite the decrease in government revenues due to the continued effects of the global financial crisis, Brazil decided not to use its SWF, though it is possible that the fund may be used in the future. More likely, Brazil's SWF fund efforts may suggest that it saw more political value in threatening the creation of a SWF than in actually implementing a SWF fund.

Apesar de sua existência por mais de meio século, os fundos soberanos de investimento apenas receberam maior atenção da comunidade internacional na virada do século. Estima-se que existam atualmente mais de 60 fundos soberanos de investimento, que movimentam capital superior a 5 trilhões de dólares. Observa-se, além disso, uma concentração geográfica desses fundos entre Oriente Médio e o Extremo Oriente. ${ }^{2}$

A vigilância mais atenta dos fundos soberanos de investimento se deve, em parte, às operações conduzidas por essas entidades. A exploradora de petróleo americana 
Unocal recebeu propostas de aquisição da China National Offshore Oil Corporation, com a participação da China Investment Corporation. Outra operação alvo de críticas foi a proposta de aquisição de portos americanos pela Dubai Ports World, controlada pelo governo dos Emirados Árabes Unidos (CARVALHO, 2009, p. 12). A China Investment Corporation também investiu três bilhões de dólares durante a oferta pública de ações, adquirindo participação de 9,9\% no grupo transnacional Blackstone, que gerencia diversos fundos private equity. A Qatar Investment Authority é controladora de 25\% da J. Sainsbury, uma das maiores redes de abastecimento de alimentos do Reino Unido. O controle de 6\% das ações da EADS, fabricante das aeronaves Airbus, é possuído pelo banco estatal russo Vneshtorgbank; outra parcela de ações é detida pelo Dubai International Capital, um dos fundos soberanos de investimento de Dubai. Os fundos soberanos de China e Cingapura adquiriram participação de 5,6\% no banco Barclays. O monopólio russo Gazprom realizou propostas de compra de dutos de gás na União Europeia (DAS, 2009, p. 93). A preocupação governamental com as interferências políticas nos fundos soberanos de investimento tem sido comumente observada nos países com economia sólida, mas também está presente nos mercados emergentes. Um exemplo é a compra da empresa tailandesa de telecomunicações Shin Corporation pela Temasek, controlada pelo governo de Cingapura, que foi fiscalizada atentamente pelo governo tailandês (HAMIDA, 2010, p. 25).

A alternativa encontrada pelos Estados para operar no mercado financeiro globalizado tem suscitado, portanto, diversos questionamentos jurídicos, que se estendem desde a forma societária escolhida para a operação dos fundos até a motivação política dos investimentos realizados por essas entidades.

O objetivo deste ensaio é avaliar especificamente os fundos soberanos de investimento a partir das questões relativas à imunidade de jurisdição. Para tanto, são apresentados os aspectos gerais - do ponto de vista jurídico e econômico - das diferentes estruturas dos fundos soberanos de investimento. Em seguida, comentam-se algumas tentativas de regulação dos fundos soberanos de investimento pelos Estados e pelas organizações internacionais. A exposição sobre os fundos soberanos de investimento serve de base para que a questão da imunidade de jurisdição seja tratada sob a perspectiva das atividades econômicas dos Estados, realizadas através de empresas estatais e bancos centrais. Após os comentários sobre casos envolvendo fundos soberanos de investimento, identificam-se, por fim, alguns critérios de análise da estrutura e da atuação dos fundos soberanos de investimento para que lhes seja concedido o benefício da imunidade de jurisdição.

\section{Aspectos gerais dos Fundos SOBERANOS DE INVESTIMENTO}

Os especialistas não alcançaram um consenso sobre a definição dos fundos soberanos de investimento, a despeito da preocupação com as consequências dessa modalidade 
de operação financeira. O Fundo Monetário Internacional, entretanto, optou por definição abrangente, classificando os fundos soberanos de investimento como "special purpose investment funds or arrangements, owned by the general government" e apontando como seus elementos fundamentais: (a) a titularidade por um governo nacional ou subnacional ${ }^{3}$ (b) a aplicação em ativos estrangeiros e (c) a realização de um objetivo financeiro macroeconômico (IMF, 2008b, p. 27). A opção do Fundo Monetário Internacional busca excluir os fundos de pensão de funcionários públicos, as operações de empresas estatais, as reservas internacionais mantidas pelas autoridades monetárias como parte de política pública e as operações de investimento no mercado interno (IMF, 2008b, p. 27).

Em outras palavras, a identificação de um fundo soberano de investimento pressupõe um conjunto de ativos financeiros de titularidade do poder público, legalmente, financeiramente e operacionalmente isolados de outras reservas financeiras públicas, cuja utilização pelos entes políticos visa a concretizar diversos objetivos econômicos, excluídos do âmbito da mera manutenção da política monetária (MEZZACAPO, 2009, p. 9-10).

$\mathrm{Na}$ verdade, sob a única denominação, os estudos econômicos relatam uma miríade de estruturas institucionais, buscando categorizar os fundos soberanos de investimentos a partir dos objetivos identificados através da análise do perfil de alocação dos ativos financeiros (MELONE, 2008, p. 150). O Fundo Monetário Internacional identifica cinco tipos de fundos soberanos de investimento de acordo com os objetivos principais estabelecidos em sua constituição: (a) os fundos de estabilização (stabilization funds), (b) os fundos de reserva para futuras gerações (savings funds for future generations), (c) as instituições de investimentos de reserva (reserve investment corporations), (d) os fundos de desenvolvimento (development funds), e (e) os fundos de reserva de pensões contingentes (contingent pension reserve funds) (IMF, 2008a, p. 5).

Os fundos de estabilização buscam neutralizar as influências da flutuação do preço de commodities no orçamento público e na economia nacional, através da constituição de uma reserva nos períodos de alta de preço para utilização nas crises econômicas. Já os fundos de reserva para futuras gerações tentam reduzir a dependência econômica da exploração de um único setor (doença holandesa), gerando uma reserva para diversificação do portfólio de ativos financeiros do Estado. As instituições de investimentos de reserva, por sua vez, têm como objetivo a maximização da rentabilidade das reservas oficiais, e os fundos de desenvolvimento têm suas reservas dirigidas ao financiamento de projetos socioeconômicos e de políticas públicas para aumentar o potencial de crescimento econômico do Estado. Por fim, os fundos de reserva de pensões contingentes constituem garantia para o pagamento de fundos de pensões, com recursos obtidos de fontes diversas da contribuição dos futuros pensionistas (MELONE, 2008, p. 152-153).

A análise dos fundos soberanos de investimento a partir da ótica da origem do capital revela outra possibilidade de classificação. Os fundos de primeira geração - 
commodity funds - são essencialmente financiados pela venda de commodities, sendo originariamente utilizados pelos países do Oriente Médio para realocar os excedentes da exploração e produção de petróleo. Os fundos de segunda geração - non commodity funds - têm sua origem no acúmulo de divisas estrangeiras nas autoridades monetárias, sendo preferidos, em momento posterior, pelos países do Extremo Oriente, com o intuito de investir os produtos do superávit da balança comercial (MEZZACAPO, 2009, p. 12).

Com efeito, o uso do capital pelos governos pode ser analisado a partir de múltiplas perspectivas, mas o ponto fundamental de qualquer análise deve ser a efetiva atividade do fundo de investimento, mais do que a denominação atribuída pelas autoridades. As classificações podem conduzir a dificuldades de conceituação, havendo sobreposição das características indicadas para cada um dos tipos de fundos soberanos de investimento (ZILINSKY, 2012, p. 2).

Verifica-se, portanto, que a compreensão total da dinâmica dos fundos soberanos de investimento é desafiante, tendo em conta a diversidade de objetivos, filosofias de investimento e ambições políticas e econômicas. Além disso, muitos fundos passam por processos de transição e reestruturação, mudanças nos padrões de alocação de ativos e realização de parcerias com corporações e instituições financeiras (BUTT, 2008, p. 73).

\section{AtuAÇÃo E REGULAÇÃo INTERNACIONAL DOS FUNDOS SOBERANOS DE INVESTIMENTO}

Ao longo de décadas, os fundos soberanos de investimento concentraram suas operações em ativos conservadores, como os títulos do tesouro norte-americano, com alta segurança e baixa rentabilidade (EPSTEIN; ROSE, 2009, p. 116). Contudo, a busca por ativos com maior rentabilidade no longo prazo produziu um aumento da tolerância ao risco e da agressividade dos investimentos (MELONE, 2008, p. 151). O portfólio foi gradualmente diversificado, havendo um percentual maior e geograficamente disperso de investimentos em participações societárias. Alguns fundos soberanos de investimento têm incluído fundos imobiliários, private equity e hedge em suas carteiras, aproximando-se da composição de carteira de grandes investidores privados (IMF, 2008a, p. 9-10).

O expressivo crescimento dos fundos soberanos de investimento traz à ordem jurídica internacional uma série de novos paradigmas de regulação e estruturação da economia global. A problemática da transparência dos fundos é um dos principais pontos discutidos pelos governos cujas empresas se tornaram alvos desses investimentos. A escassez de informações públicas e confiáveis acerca do volume financeiro dos fundos bem como a indefinição sobre seus reais objetivos têm criado incertezas nos países hospedeiros dos investimentos, que questionam a estrutura institucional, as políticas de investimento e o gerenciamento de risco dos fundos. 
Além disso, considerando o elevado volume de capital controlado por alguns fundos soberanos de investimento, observa-se a preocupação acerca das consequências que as mudanças repentinas de fluxo de capital, em função da realocação de ativos financeiros, podem causar no equilíbrio econômico internacional, através, por exemplo, de súbitas alterações de preço. Alguns analistas de mercado notam ainda que a crescente participação dos fundos soberanos de investimento nos mercados internos pode dar margem à reversão da tendência de privatização das últimas décadas. As projeções apontam para a crescente aquisição de controle societário por governos estrangeiros ou por entidades controladas por esses governos, abrindo caminho para reações protecionistas, as quais causariam medidas e contramedidas de retaliação, conduzindo a uma reversão do quadro de multilateralismo no comércio internacional.

Nesse sentido, a Comissão Europeia realizou estudos para determinar se a proliferação de grandes fundos soberanos de investimento ameaça o mercado único do continente. As conclusões da Comissão Europeia (2008) podem ser assim sintetizadas:

Não obstante o facto de serem reconhecidas as vantagens inerentes aos investimentos realizados pelos fundos soberanos, alguns países destinatários manifestaram preocupações neste contexto, incluindo na UE. [...] Uma preocupação mais específica suscitada pelos investimentos em acções, realizados pelos fundos soberanos, prende-se com a falta de transparência do funcionamento de alguns fundos e a sua eventual utilização como instrumento para adquirir um controlo estratégico. [...] A abordagem comum da UE deverá representar uma contribuição para os trabalhos do FMI no sentido de criar um código de conduta para os fundos soberanos e os seus países detentores, bem como para os trabalhos desenvolvidos pela OCDE com vista à formulação dos princípios a aplicar pelos países destinatários nas suas relações com estes fundos.

Alguns países europeus discutiram a adoção de uma política de bloqueio ao controle de empresas nacionais por fundos soberanos de investimento estrangeiros. As autoridades financeiras da Alemanha, por outro lado, cogitaram a criação de uma legislação para bloquear completamente o investimento realizado por fundos soberanos de investimento, optando posteriormente por adotar uma medida de controle mais estrito para as aquisições de participação superior a 25\% nas empresas alemãs (SCHWAB, 2008). Os Estados Unidos revisaram a legislação concernente ao Comitê Americano para Investimento Estrangeiro, com o foco específico no estabelecimento de diretrizes regulatórias para o investimento de entidades ligadas a governos estrangeiros (TRUMAN, 2007, p. 7).

A regulação pelo Estado hospedeiro enfrenta, entretanto, duas grandes dificuldades estruturais. A primeira é interna: a intensidade da regulação é diretamente 
proporcional à diminuição da atração de capital estrangeiro. A segunda é internacional: as atitudes protecionistas afetam a integridade dos mercados globais. Diante da dificuldade de regulação no Estado hospedeiro, uma proposta de solução consiste na busca de termos regulatórios comuns que pudessem ser postos em prática pelos Estados de origem (BACKER, 2010, p. 93).

Os governos pressionaram, nessa perspectiva, a comunidade jurídica internacional para a formulação de um "código de conduta" dos fundos soberanos de investimento. Muitos países consideram o fortalecimento das estruturas regulatórias essencial para harmonizar a complexa interligação entre soberania, abertura de mercados, economia globalizada, proteção de investimentos e equilíbrio dos mercados internos. Um sistema de regulação efetivo seria aquele capaz de verificar a fonte dos recursos financeiros, analisar os objetivos do projeto de investimento e preparar estratégias jurídicas para garantir, por um lado, a estabilidade de setores estratégicos e, por outro, a contínua atração de novos investidores (GARTEN, 2007).

Dessa forma, em outubro de 2007, alguns países se alinharam na defesa de um conjunto de boas práticas a serem voluntariamente observadas pelos fundos soberanos. A única solução possível parecia ser um sistema de autorregulação baseado em instrumentos de soft law. A intenção da regulação era reunir parâmetros de conduta e mecanismos de governança e de transparência capazes de, ao menos, reduzir a aparência de uma intenção política mascarada nas atividades financeiras dos fundos soberanos de investimento. A intenção era também fornecer uma base jurídica, ainda que com natureza de soft law, à qual, no longo prazo, se exigiria maior adequação por parte dos fundos soberanos. Uma vez estabelecidas, essas normas também poderiam fornecer um paradigma para futuras leis nacionais (BACKER, 2010, p. 87).

Em maio de 2008, o Grupo de Trabalho Internacional de Fundos Soberanos de Investimento (International Working Group of Sovereign Wealth Funds) foi criado como resposta às pressões no âmbito do G-8, reunindo representantes de fundos soberanos de 23 países. ${ }^{4}$ O Fundo Monetário Internacional passou a secretariar o Grupo de Trabalho Internacional, cuja tarefa era identificar e elaborar um conjunto de princípios e práticas geralmente aceitos (generally accepted principles and practices) que refletisse adequadamente as expectativas dos Estados de origem e dos Estados hospedeiros.

As negociações conduziram à adoção dos denominados Princípios de Santiago em outubro de 2008, que, embora minimizando as divergências de opinião entre os Estados de origem dos fundos soberanos, contribuíram significativamente para a criação de referências de comportamento aceitável. O Grupo de Trabalho Internacional assinala que a finalidade dos Princípios de Santiago é a identificação de um conjunto de princípios e práticas geralmente aceitos, que reflete mecanismos adequados de governança e responsabilidade bem como práticas de investimento dos fundos soberanos, em uma perspectiva prudente e razoável. No original: "identify[ing] a framework of generally accepted principles and practices that properly reflect appropriate governance and 
accountability arrangements as well as the conduct of investment practices by SWFs on a prudent and sound basis" (IMF, 2008b).

Os Princípios de Santiago abrangem práticas e princípios em três áreas fundamentais: (i) aspectos jurídicos, objetivos do investimento e políticas macroeconômicas; (ii) aspectos institucionais e governança; e (iii) estrutura de gerenciamento de riscos e de investimentos. O documento contém 24 princípios sob a forma de recomendações para a atuação tanto dos fundos soberanos de investimento quanto dos Estados hospedeiros (IMF, 2008b).

Após a publicação dos Princípios de Santiago, o Grupo de Trabalho Internacional de Fundos Soberanos de Investimento considerou encerrados seus trabalhos e determinou, em abril de 2009, através da Declaração do Kuwait - resultado da conferência realizada na cidade homônima - a criação do Fórum Internacional de Fundos Soberanos de Investimento (International Forum of Sovereign Wealth Funds). O Fórum Internacional reúne os membros originários do Grupo de Trabalho Internacional, juntamente com o representante de fundos soberanos da Malásia. Importante observar que, embora o Fórum Internacional possua representação de apenas 24 países, os fundos soberanos com os maiores volumes financeiros estão reunidos na entidade. ${ }^{5}$

Em junho de 2011, o Fórum Internacional publicou um relatório sobre a implementação dos Princípios de Santiago por seus membros, baseado nas declarações de seus fundos soberanos, apontando que $95 \%$ das práticas dos fundos soberanos estavam de acordo com os Princípios de Santiago. O relatório concluiu que (a) os membros representam um grupo heterogêneo, de maneira que não é possível ter expectativas uniformes sobre a implementação dos princípios; (b) em função da heterogeneidade, os membros têm abordagens distintas quanto aos princípios, uma vez que se submetem a ordenamentos jurídicos específicos; (c) os princípios representam um guia útil aos membros; e (d) embora a maioria dos membros esteja agindo em conformidade com os princípios, novos progressos são necessários, especialmente no que tange às revisões periódicas dos princípios (IMF, 2011).

Em paralelo, após a publicação do relatório do Investment Committee da Organização para Cooperação e Desenvolvimento Econômico (OCDE), o Ministerial Council da organização adotou, em junho de 2008, a Declaração sobre Fundos Soberanos de Investimento e Políticas dos Estados Hospedeiros. A Declaração não afasta a regulação dos fundos soberanos pelos Estados hospedeiros, recomendando apenas a não adoção de barreiras protecionistas. A eventual regulação pelo Estado hospedeiro deve ser transparente, previsível, proporcional e não discriminatória. No texto original da declaração (OECD, 2008):

Recipient countries should not erect protectionist barriers to foreign investment. Recipient countries should not discriminate among investors in like circumstances. Any additional investment restrictions in recipient countries should 
only be considered when policies of general application to both foreign and domestic investors are inadequate to address legitimate national security concerns. Where such national security concerns do arise, investment safeguards by recipient countries should be: (1) transparent and predictable, (2) proportional to clearly-identified national security risks, and (3) subject to accountability in their application.

De maneira análoga aos Princípios de Santiago, a Declaração não é vinculante, devendo ser implementada por cada um dos países membros interessados (BADIAN; HARRINGTON, 2009, p. 151).

À luz do exposto, constata-se a dificuldade de regulação dos fundos soberanos de investimento. Mesmo na esfera internacional a tarefa afigura-se extremamente complexa, porquanto o objeto de regulação ainda não é completamente conhecido. Os fundos soberanos de investimento circunscrevem, na realidade, diversas estruturas institucionais - de empresas controladas pelo Estado a entidades despersonificadas vinculadas ao governo central - e variadas estratégias de investimento - da operação indireta em mercados de capitais à aquisição de controle em setores estratégicos. Nesse panorama, uma das muitas questões sobre os fundos soberanos de investimento - para a qual uma resposta ainda não foi encontrada - é a possibilidade de essas entidades invocarem a imunidade de jurisdição para as operações realizadas em Estados estrangeiros.

\section{A imunidade de jurisdição}

\section{E AS ATIVIDADES ECONÔMICAS DOS ESTADOS}

A soberania consiste na superioridade do poder estatal em relação a todos os demais existentes em seu território, traduzindo-se especialmente na possibilidade de edição e imposição de um ordenamento jurídico próprio. Na esfera internacional, a soberania se caracteriza pela inserção do Estado na ordem internacional em situação de igualdade formal com os demais Estados. A imunidade de jurisdição decorre, por sua vez, da dimensão internacional da soberania, materializando a ideia de que um Estado, por ser formalmente igual a todos os outros, não pode ser submetido a decisões que emanem de outros Estados. A regra tem base consuetudinária com origem na cláusula par in parem non habet imperium (TIBURCIO, 2006).

Ao longo dos anos, a teoria da imunidade absoluta evoluiu para a teoria da imunidade relativa, segundo a qual, em certas situações, um Estado pode ser julgado por outro sem violação a sua soberania, já que nem sempre o Estado atua no uso de suas prerrogativas de império.

De acordo com Jacob Dolinger (1982, p. 10):

Após a $1^{\text {a }}$ Guerra Mundial coexistiam duas teorias sobre a imunidade 
estatal nas jurisdições estrangeiras: a da imunidade absoluta e a da imunidade restrita, ou relativa, que concedia imunidade aos Estados em relação a seus atos soberanos ou públicos (jus imperii), mas recusava o privilégio a seus atos privados ou comerciais (jus gestionis). Esta segunda teoria foi ganhando terreno, suplantou a teoria clássica da imunidade absoluta, que praticamente não mais influencia o direito atual.

A teoria da imunidade relativa criou, entretanto, a necessidade de se estabelecer a diferença entre ato de império e ato de gestão, produzindo uma controvérsia substancial, pois nem sempre é fácil identificar quando o Estado age na condição de ente soberano, utilizando seus atributos de império, ou quando a organização estatal atua como simples particular, em ato de comércio. Desenvolveram-se dois critérios para sistematizar a distinção: o da natureza do ato e o da finalidade do ato. Os resultados decorrentes de cada um destes critérios são frequentemente divergentes (MOLL, 2010, p. 25).

Para tentar afastar a insegurança e as disparidades das decisões dos tribunais, os diplomas mais recentes têm evitado o emprego puro e simples das vagas expressões "atos de império" e "atos de gestão" para determinar as hipóteses em que o Estado merece o benefício de imunidade (MOLL, 2010, p. 32). A previsão de imunidade de jurisdição como regra e a utilização de uma exceção à imunidade de jurisdição, nos casos de atuação comercial ou privada, são as marcas da abordagem da teoria da imunidade relativa. A exceção toma como pressuposto que, quando um Estado está envolvido em uma transação comercial, ele deixa de atuar em sua capacidade soberana e perde o direito ao benefício da imunidade de jurisdição para as transações comerciais (GAUKRODGER, 2010, p. 10).

A legislação e os tribunais nacionais interpretam e aplicam as regras sobre imunidade de jurisdição com significativas variações. Em virtude disso, a comunidade internacional tentou por muitos anos chegar a um consenso sobre o assunto. O primeiro tratado multilateral a ser concluído sobre imunidade de jurisdição foi a Convenção Europeia sobre a Imunidade dos Estados, que entrou em vigor em 1976. No entanto, apenas Alemanha, Áustria, Bélgica, Chipre, Luxemburgo, Holanda, Suíça e Reino Unido são partes da Convenção (GAUKRODGER, 2010, p. 10).

A negociação de um tratado mais amplo era extremamente difícil. Após décadas de negociações, um acordo foi finalmente alcançado em 2004, com a Convenção das Nações Unidas sobre Imunidades Jurisdicionais dos Estados, adotada pela Assembleia Geral das Nações Unidas e aberta à assinatura em dezembro de 2004. A Convenção prevê a entrada em vigor quando trinta Estados apresentarem a sua ratificação, aceitação, aprovação ou adesão junto do Secretário-Geral das Nações Unidas. Vinte e oito Estados assinaram o tratado durante o período aberto à assinatura, mas apenas treze (Alemanha, Áustria, Arábia Saudita, Espanha, Irã, Cazaquistão, Líbano, Noruega, 
Portugal, Romênia, França, Japão e Suécia) ratificaram ou aderiram à Convenção (GAUKRODGER, 2010, p. 10).

$\mathrm{O}$ artigo $5^{\circ}$ da Convenção das Nações Unidas prevê o reconhecimento da imunidade de jurisdição como princípio de atuação dos Estados, com observância das exceções previstas na própria Convenção. Uma das exceções, contida no artigo 10, se refere às transações comerciais efetuadas no Estado do foro, para as quais o Estado não pode invocar imunidade de jurisdição, a não ser quando a transação tenha sido realizada entre Estados ou quando as partes tenham acordado no sentido de reconhecer a imunidade. O parágrafo $3^{\circ}$ do artigo 10 determina que a imunidade do Estado não é afetada quando uma empresa ou entidade estatal, com personalidade jurídica e capacidade processual apartadas, está envolvida na transação. Em sentido análogo, o artigo 15 da Convenção afasta a imunidade de jurisdição do Estado para os litígios relativos a participações em empresas ou em outros organismos, mesmo os sem personalidade jurídica, quando (a) os participantes não sejam exclusivamente Estados e organizações internacionais e (b) a incorporação, a constituição, a sede ou o centro de negócios principal tenha lugar no Estado do foro.

É interessante observar que a teoria da imunidade relativa prioriza a natureza da operação em detrimento da estrutura da entidade que a realiza. É dizer: ao Estado e a seus entes é reconhecida a imunidade de jurisdição em função da operação realizada, mais do que em função da estrutura institucional apresentada. No entanto, a estrutura da entidade ainda é de grande importância no que diz respeito aos fundos soberanos de investimento. Em primeiro lugar, embora o questionamento possa ter se deslocado para a natureza da operação, em muitos casos a independência estrutural e operacional da entidade em relação ao Estado pode ser um fator importante na caracterização do ato como soberano ou comercial. Em segundo lugar, ainda que a estrutura possa ser de importância secundária em relação à imunidade de jurisdição, sua importância ressurge em relação à imunidade de execução (GAUKRODGER, 2010, p. 14-15).

Nesse sentido, cumpre lembrar que os fundos soberanos de investimento podem apresentar diversas estruturas institucionais. A primeira distinção estrutural é realizada entre os fundos personificados - como aqueles da China, dos Emirados Árabes Unidos, da Austrália e de Cingapura - e os despersonificados - a exemplo do Chile, da Noruega, da Rússia e do Brasil. Entre os fundos despersonificados, a função de gerenciamento dos ativos pode ser delegada a um órgão administrativo do governo central - um ministério, uma comissão parlamentar ou uma agência reguladora específica - ou a um banco central (GAUKRODGER, 2010, p. 14-15).

Cabe, em virtude disso, comentar as distinções entre fundos soberanos de investimento e as entidades que lhe são mais próximas: as empresas estatais e os bancos centrais. O principal parâmetro para distinguir os fundos soberanos das empresas estatais é a estrutura organizacional. Os fundos soberanos apresentam-se como conjunto de ativos titularizados pelo governo com o objetivo de promover políticas de 
interesse nacional, ao passo que as empresas estatais são pessoas jurídicas separadas direcionadas à execução de atividade comercial. A distinção, entretanto, é ineficaz. A China Investiment Corporation - fundo soberano de investimento da China - apresenta, por exemplo, personalidade jurídica distinta nos termos da lei chinesa, mas tal caracterização não permite enxergá-la como uma empresa estatal. Outro parâmetro utilizado para distinguir os fundos soberanos das empresas estatais é a fonte dos recursos empregados nas operações. Com esse critério, tanto os fundos como as empresas poderiam realizar atividades semelhantes, mantendo as fontes dos recursos em separado. A distinção se mostra igualmente inadequada, porquanto a fonte principal de recursos de ambas as entidades é o Estado controlador (BACKER, 2010, p. 64-66).

Essas tentativas demonstram que as distinções formais podem disfarçar convergências funcionais. Ainda que a distinção possa parecer superficialmente óbvia, as empresas estatais atuam, muitas vezes, como um prolongamento dos fundos soberanos, integrando uma cadeia de entidades responsáveis simultaneamente pelas políticas econômicas do Estado e por suas transações comerciais. A diferença sutil parece estar mais intimamente relacionada à função dessas entidades: os fundos soberanos são criados para desempenhar precipuamente a atividade de investimento do Estado soberano, ao passo que as empresas estatais atuam em outras áreas. Entretanto, as empresas estatais podem realizar investimentos, aproximando-se, ainda que indiretamente, de um fundo soberano. De outra parte, os fundos soberanos de investimento podem adquirir o controle e a gestão de empresas estrangeiras, realizando funções de uma empresa estatal controladora (BACKER, 2010, p. 64-66).

No que tange aos bancos centrais, há grande diversidade de tratamento pelos ordenamentos jurídicos nacionais. Há uma crescente tendência, todavia, em reconhecer a imunidade de execução - e, por vezes, a imunidade de jurisdição - a essas entidades. A questão é relevante para a análise, uma vez que muitos fundos soberanos de investimento estão subordinados ou são parte integrante dos bancos centrais.

Algumas jurisdições não preveem proteção especial para os bancos centrais. $\mathrm{Na}$ Alemanha, por exemplo, a execução de contas do banco central da Nigéria foi autorizada pelo Tribunal de Frankfurt em caso de 1975. A corte entendeu, na ocasião, que os ativos não utilizados naquele momento para uma finalidade pública não poderiam gozar de imunidade. Em outra ocasião, o Tribunal Federal da Suíça negou imunidade aos ativos do banco central da Líbia, rejeitando o argumento de que os valores poderiam ser considerados reservas de moeda para fins de imunidade (GAUKRODGER, 2010, p. 24). ${ }^{6}$

Outros países, contudo, concedem diferentes níveis de proteção aos bancos centrais. A lei chinesa, por exemplo, prevê expressamente imunidade aos bancos centrais. De maneira semelhante, a legislação francesa concede imunidade a todos os bens, de qualquer natureza, titularizados ou gerenciados pelo banco central ("leurs biens de toute 
nature [qu'elles]... détiennent ou gèrent pour leur compte ou celui de l'Etat ou des Etats étrangers dont elles relèvent"). Nos Estados Unidos, o Foreign Sovereign Immunities Act considera imunes todos os ativos de bancos centrais "held for its own account".

No plano convencional, a Convenção das Nações Unidas sobre Imunidades Jurisdicionais dos Estados, embora ainda não em vigor, garante imunidade de jurisdição aos bancos centrais por força do artigo 21, que afasta o caráter comercial da propriedade de bancos centrais.

Considerando as interpenetrações de conceitos, verifica-se que os fundos soberanos de investimento se situam entre os bancos centrais - com os quais compartilham alguns objetivos - e as empresas estatais - com as quais compartilham alguns instrumentos. A perquirição sobre a imunidade de jurisdição dos fundos soberanos de investimento depende de caracterizar os fundos como investidores privados ou empresas estatais, aos quais normalmente a imunidade de jurisdição não é reconhecida; ou, por outro lado, como bancos centrais ou órgãos do Estado, para os quais a imunidade de jurisdição estaria garantida (BASSAN, 2011, p 89).

\section{A Imunidade de JURISDiÇÃo de FUndos SOBERANOS DE INVESTIMENTO: PARÂMETROS DE ANÁLISE}

A fragmentação no tratamento dispensado pelos Estados às entidades que realizam atividades econômicas - empresas estatais e bancos centrais - permite entrever respostas ambíguas quanto aos fundos soberanos de investimento, os quais, além de apresentarem grande variação estrutural, podem desempenhar funções de soberania, ainda que, por vezes, realizem operações consideradas comerciais, para fins de exceção à imunidade de jurisdição.

Não há notícia de um tratamento legislativo expresso sobre a extensão da imunidade de jurisdição aos fundos soberanos de investimento, de maneira que a resposta deve ser buscada na análise de casos concretos. A esse respeito, frise-se que há registros de apenas dois casos envolvendo diretamente a imunidade de jurisdição ou a imunidade de execução de fundos soberanos de investimento, os quais não oferecem uma resposta conclusiva.

No caso Sarrió S.A. v. Kuwait Investment Authority, a empresa espanhola Sarrió S.A. propôs ação em face da Kuwait Investment Authority, cujo escritório de representação tinha sede em Londres, sob a denominação Kuwait Investment Office. A ação versava sobre danos causados à empresa em decorrência de informações falsas durante a fase de negociações. O processo foi extinto pela Câmara dos Lordes, uma vez que existia um processo pendente na justiça espanhola. $\mathrm{O}$ tribunal britânico entendeu prorrogada a jurisdição espanhola, nos termos do artigo 22 da Convenção de Bruxelas.

Os fatos do caso apontam que parte das ações da empresa espanhola Sarrió S.A. haviam sido adquiridas pelo Grupo Torras, o qual, embora incorporado na Espanha, 
tinha 96\% de suas ações controladas pela Kuwait Investment Authority. Em virtude de um inadimplemento contratual, a empresa ingressou com ação em face de litisconsórcio passivo composto pelo Grupo Torras e pela Kuwait Investment Authority/Kuwait Investment Office. Posteriormente o Grupo Torras iniciou uma "suspensión de pagos" uma espécie de insolvência -, pelo que a empresa espanhola buscou caracterizar a responsabilidade do fundo soberano do Kuwait (GAUKRODGER, 2010, p. 16).

A empresa espanhola, paralelamente, obteve junto ao Judiciário suíço uma espécie de penhora prévia (pre-judgment attachment) das contas da Kuwait Investment Authority em bancos de Genebra e Zurique. Os tribunais suíços rejeitaram a imunidade de jurisdição invocada pelo Kuwait, cujo argumento buscava caracterizar os ativos presentes nos bancos suíços como parte de um fundo soberano para gerações futuras, composto por receitas da exploração de petróleo (GAUKRODGER, 2010, p. 16-17).

Além disso, os tribunais suíços consideraram que a transação realizada na Espanha tinha natureza comercial - afastando a imunidade de jurisdição - e que as contas bancárias estavam em nome da Kuwait Investment Authority/Kuwait Investment Office, uma entidade separada e independente do Estado recorrente (Kuwait) -, afastando também a imunidade de execução (GAUKRODGER, 2010, p. 17).

Em caso posterior sobre a imunidade de jurisdição de fundos soberanos - AIG Capital Partners Inc and another v. Republic of Kazakhstan -, a abordagem das cortes britânicas foi diferente. No caso, a AIG Capital Partners havia obtido um laudo arbitral do International Centre for Settlement of Investment Disputes (ICSID), condenando a República do Cazaquistão. A empresa buscava então executar valores mobiliários do Banco Nacional do Cazaquistão custodiados por um banco de Londres. Havia dezesseis contas bancárias em Londres, contendo ativos como títulos públicos britânicos, ações de empresas negociadas na bolsa de Londres e títulos estrangeiros que eram comercializados 6.700 vezes por mês.

A empresa sustentava que as transações financeiras estavam inseridas no conceito de transação comercial, o que afastaria a imunidade dos ativos custodiados pelo banco inglês. A República do Cazaquistão aduziu que as transações eram parte do objetivo soberano do National Fund of Kazakhstan, controlado diretamente pelo governo daquele Estado, e que apenas a operação dos ativos era delegada ao banco central. O chefe da missão diplomática da República do Cazaquistão junto ao Reino Unido enviou carta às cortes britânicas, certificando que os ativos eram diretamente controlados pelo governo do Cazaquistão e faziam parte do fundo soberano de estabilização daquele país.

A corte britânica considerou que a tolerância ao risco e a operação pelo banco central não eram determinantes para afastar a imunidade, uma vez que os ativos não eram utilizados para finalidades comerciais, pois o objetivo geral era garantir o National Fund of Kazakhstan. Nesse sentido, o tribunal concluiu que as transações eram parte do exercício da autoridade soberana da República do Cazaquistão ("the dealings are all part of the overall exercise of sovereign authority by the Republic of Kazakhstan"). 
Verifica-se que, embora as transações pudessem ser realizadas por entes privados, a decisão analisou a aquisição dos valores mobiliários a partir da perspectiva de seu objetivo. Ao considerar que a manutenção de ativos nos banco inglês era parte das atividades do National Fund of Kazakhstan, com base nos objetivos por ele indicados, o tribunal britânico ampliou drasticamente a imunidade de execução e, possivelmente, a imunidade de jurisdição dos fundos soberanos de investimento. Se a mesma lógica for utilizada em outras cortes para casos futuros, os fundos soberanos de investimento estarão, independentemente de sua estrutura, protegidos pela imunidade de jurisdição.

A análise da escassa jurisprudência evidencia a necessidade de buscar uma sistematização para análises de futuros casos, em que se pleiteie o benefício da imunidade de jurisdição para os fundos soberanos de investimento.

Um primeiro passo nesse sentido é verificar se o fundo soberano de investimento se caracteriza diretamente como um Estado estrangeiro ou, ao menos, como uma parte desse Estado estrangeiro. Os fundos soberanos de investimento despersonificados e vinculados diretamente ao Estado ou a um de seus órgãos governamentais diretos parecem incluir-se nesse grupo e poderiam, em tese, gozar do benefício de imunidade de jurisdição concedido ao Estado. Vale lembrar que, em muitos países, os fundos soberanos de investimento gozam de imunidade tributária, indicando significativamente que são considerados entidades soberanas estrangeiras (SLAWOTSKY, 2009, p. 996-997).

Em segundo lugar, é preciso ressaltar, contudo, que alguns fundos soberanos de investimento têm personalidade jurídica separada do Estado, mas ainda assim poderiam invocar o benefício da imunidade de jurisdição. É o caso, no direito norte-americano, da "agency or instrumentality of a foreign state" prevista no $\S 1603(\mathrm{~b})$ do Foreign Sovereign Immunities Act. Trata-se da entidade incorporada no Estado estrangeiro cujo controle seja majoritária ou totalmente do Estado estrangeiro. Foram incluídas nesse conceito, por estarem sobre controle majoritário ou absoluto do Estado estrangeiro, diversas entidades como empresas aéreas nacionais, empresas de energia nuclear, empresas de telecomunicações, bancos centrais, bancos comerciais, empresas ferroviárias (SLAWOTSKY, 2009, p. 994-995).

Em ambos os casos, é preciso analisar as eventuais exceções existentes para a concessão do benefício da imunidade de jurisdição. Uma relevante exceção é a das transações comerciais, a exemplo do § 1605(a)(2) do Foreign Sovereign Immunities Act. De acordo com o $§ 1603$ (d) do mesmo diploma, uma atividade comercial "means either a regular course of commercial conduct or a particular commercial transaction or act. The commercial character of an activity shall be determined by reference to the nature of the course of conduct or particular transaction or act, rather than by reference to its purpose". Em que pese a definição da exceção, as cortes norte-americanas já reconheceram a dificuldade de sua aplicação concreta, chegando a concluir, no caso Najarro de Sanchez v. Banco Central de Nicaragua, que um banco central estrangeiro, mesmo atuando de 
forma semelhante a um particular, estaria agindo com um propósito diferente, tornando a natureza da operação igualmente diferente (SLAWOTSKY, 2009, p. 999-1000).

Revela-se, a partir dessa análise, que as hipóteses de concessão do benefício da imunidade de jurisdição aos fundos soberanos de investimento não podem ser determinadas em abstrato: uma análise casuística é imprescindível para essa finalidade. A diversidade estrutural dos fundos soberanos de investimento não permite mais do que a simples fixação de alguns parâmetros de análise no caso concreto.

O primeiro parâmetro é o da estrutura jurídica do fundo soberano de investimento. Para determinar se a entidade se aproxima mais do Estado ou de um investidor privado, é necessário avaliar, entre outros fatores, a personalidade jurídica, a incorporação, as funções, os poderes, as atividades, a governança e a relação com o Estado. O segundo parâmetro é o do objetivo do fundo soberano. Apesar da diversidade de objetivos, é preciso verificar se a entidade tem relevância estratégica para a materialização de alguma política pública macroeconômica do Estado estrangeiro. O terceiro parâmetro é o da política de financiamento. A origem dos recursos do fundo soberano e as regras para o resgate de ativos servem de indicativos para reforçar o papel da entidade nas políticas do Estado estrangeiro. O resgate de ativos do fundo para financiamento de obras públicas de infraestrutura revela, por exemplo, um objetivo soberano relevante, se comparado ao resgate de ativos para gastos com recepções para convidados do governo. O quarto parâmetro é o da natureza dos investimentos. Nesse âmbito, a avaliação deve considerar globalmente a estratégia de investimento do fundo soberano, para verificar se ela se alinha com a materialização de objetivos soberanos, como a estabilização ou a geração de riqueza, ou se ela disfarça objetivos políticos ou especulativos. O quinto parâmetro é o do objetivo do ativo financeiro. Essa etapa tem maior relevância para a concessão da imunidade de execução, porquanto a análise é restrita ao ativo individualmente considerado (BASSAN, 2011, p. 111-114).

Os tribunais brasileiros e os de muitos outros países ainda não tiveram oportunidade de enfrentar a questão, mas a experiência ainda incipiente dos casos relatados permite vislumbrar esses parâmetros, que não servem senão para auxiliar as cortes a analisar os fundos soberanos de investimento quando da invocação do benefício da imunidade de jurisdição.

\section{CONCLUSÃO}

Embora existam há décadas, os fundos soberanos de investimento apresentaram crescimento mais acentuado nos últimos anos. Além disso, esses fundos desenvolveram estratégias de investimento que passaram a receber maior atenção por parte dos Estados. O fenômeno econômico é acompanhado por um relativo atraso regulatório: não há ainda sequer uma definição universalmente aceita para os fundos soberanos de 
investimento, e os conceitos atualmente utilizados acabam subestimando, em função da tentativa de generalização, algumas das características institucionais dos diversos tipos de fundos soberanos existentes. A regulação nacional esbarra em tantas dificuldades quanto a regulação internacional, que se limita a instrumentos de soft law, em iniciativas capitaneadas pelo Fundo Monetário Internacional e pela Organização para Cooperação e Desenvolvimento Econômico.

Uma das diversas questões controversas sobre os fundos soberanos de investimento é a possibilidade de invocação do benefício da imunidade de jurisdição. Verifica-se que os fundos soberanos de investimento se situam entre os bancos centrais - com os quais compartilham alguns objetivos - e as empresas estatais - com as quais compartilham alguns instrumentos. Definir em qual dessas direções os fundos soberanos se inclinam é de fundamental importância para a concessão da imunidade de jurisdição.

A fragmentação do tratamento legislativo e jurisprudencial concedido a empresas estatais e bancos centrais produz respostas contraditórias quanto aos fundos soberanos de investimento. A irrisória jurisprudência específica sobre esses fundos tampouco oferece respostas conclusivas, mas permite extrair alguns parâmetros de análise no caso concreto, uma vez que - ao menos no futuro próximo - a questão continuará sendo tratada concretamente. O sucesso de aplicação desses parâmetros de análise dos fundos soberanos de investimento depende, contudo, da existência e da efetividade dos mecanismos de controle e transparência.

: ARTIGO APROVADO (13/11/2013) : RECEBIDO EM 26/11/2012

NOTAS

1 Para informações atualizadas sobre os volumes financeiros e anos de incorporação, cf. http://www.swfinstitute.org/. Acesso em: 20 jul. 2012. A Noruega foi pioneira, em 1990, na criação de um fundo soberano na Europa, utilizando os produtos da exploração de petróleo e, posteriormente, diversificando as fontes de financiamento.

2 Dados disponíveis em: <http://www.swfinstitute.org/fund-rankings/>. Acesso em: 20 jul. 2012.

3 Exemplos de fundos subnacionais são: Texas Permanent School Fund, New Mexico State Investment Council e Alaska Permanent Fund. Dados disponíveis em: <http://www.swfinstitute.org/fund-rankings/>. Acesso em: 19 ago. 2012.

4 Os países originalmente representados foram: Austrália, Azerbaijão, Bahrein, Botswana, Canadá, Chile, China, Guiné Equatorial, Irã, Irlanda, Coreia do Sul, Kuwait, Líbia, México, Nova Zelândia, Noruega, Qatar, Rússia, Cingapura, Timor-Leste, Trinidad e Tobago, Emirados Árabes Unidos e Estados Unidos da América. 
5 Para maiores informações sobre o International Forum of Sovereign Wealth Funds, consultar http: / /www.ifswf.org. Acesso em: 16 set. 2012 .

6 Os casos são: Central Bank of Nigeria, Landsgericht Frankfurt, (2 December 1975), 65 ILR 131; e Libya v. Actimon SA, Swiss Federal Tribunal (24 April 1985), 82 ILR 30.

\section{REFERÊNCIAS BIBLIOGRÁFICAS}

AIG Capital Partners Inc. and Another v. Kazakhstan, [2005] EWHC 2239 (Comm), [2006] 1 All ER (Comm) 1. BACKER, Larry Catá. Sovereign investing in times of crisis: global regulation of sovereign wealth funds, state-owned enterprises, and the Chinese experience. Transnational Law \& Contemporary Problems, v. 19, n. 1, p. 3-144, 2010. BADIAN, Laura; HARRINGTON, Gregory. The evolving politics of sovereign wealth funds. Revue d'Économie Financière, p. 143-156, 2009

BASSAN, Fabio. The law of sovereign wealth funds. Cheltenham: Edward Elgar Publishing, 2011.

BUTT, Shams et al. Sovereign Wealth Funds: A growing global force in corporate finance. Journal of Applied Corporate Finance, v. 20, n. 1, p. 73-83, 2008.

CAPARICA, Rodrigo Ferreira de Carvalho. O papel dos fundos soberanos na economia mundial. Dissertação [Mestrado em Finanças e Economia Empresarial]. Fundação Getulio Vargas, Rio de Janeiro, 2010.

CARVAlHO, Fernando J. Cardim de. Fundo Soberano Brasileiro. Le Monde Diplomatique Brasil, São Paulo, fevereiro de 2009, p. 12.

COMISSÃO EUROPEIA. Abordagem europeia comum em matéria de fundos soberanos. [COM(2008) 115]. Bruxelas, 2008. DAS, Dilip K. Sovereign-wealth funds: the institutional dimension. Int. Rev. Econ., v. 56, p. 85-104, 2009.

DOLINGER, Jacob. A imunidade jurisdicional dos Estados. Revista de Informação Legislativa, v. 19, n. 76, out./dez. 1982. EPSTEIN, Richard A.; ROSE, Amanda M. The regulation of sovereign wealth funds: the virtues of going slow.

The University of Chicago Law Review, v. 76, n. 1, p. 111-134, 2009.

ESTADOS UNIDOS DA AMÉRICA. Foreign Sovereign Immunities Act, 1976.

GARTEN, Jeffrey. We need rules for sovereign funds. Financial Times, 8 de agosto de 2007.

GAUKRODGER, David. Foreign State immunity and foreign government controlled investors. OECD Working Papers on International Investment, n. 2, 2010.

HAMIDA, Walid Ben. Sovereign FDI and international investment agreements: questions relating to the qualification of sovereign entities and the admission of their investments under investment agreements. The Law and Practice of International Courts and Tribunals, v. 9, p. 17-36, 2010.

IMF - INTERNATIONAL MONETARY FUND. IFSWF members' experiences in the application of the Santiago Principles. [s.1.], 2011.

IMF - INTERNATIONAL MONETARY FUND. Sovereign wealth funds: a work agenda. [s.1.], 2008a.

Sovereign wealth funds: generally accepted principles and practices (Santiago Principles). [s.1.], 2008b.

MELONE, Matthew A. Should the United States tax sovereign wealth funds? Boston University International Law Journal, v. 26, p. 143-225, 2008.

MEZZACAPO, Simone. The so-called "sovereign wealth funds": regulatory issues, financial stability, and prudential supervision. Economic Papers, n. 378, p. 1-104, 2009.

MOLL, Leandro de Oliveira. Imunidades internacionais: tribunais nacionais ante a realidade das organizações internacionais. 2.ed. Brasília: FUNAG, 2010.

OECD - ORGANISATION FOR ECONOMIC COOPERATION AND DEVELOPMENT. OECD Declaration on sovereign wealth funds and recipient country policies. [s.1.], 2008.

REPÚBLICA FRANCESA. Loi n 2005-842 du 26 juillet 2005 pour la confiance et la modernisation de l'économie. REPÚBLICA POPULAR DA CHINA. Law of the People's Republic of China on Judicial Immunity from Compulsory Measures Concerning the Property of Foreign Central Banks. 25 de outubro de 2005.

Sarrió SA v. Kuwait Investment Authority, [1997] UKHL 49, [1997] 4 All ER 929.

SCHWAB, Andreas. Les fonds souverains. [Discurso]. Estrasburgo, 22 de outubro de 2008.

SLAWOTSKY, Joel. Sovereign wealth funds and jurisdiction under the FSIA. University of Pennsylvania Journal of Business Law, v. 11, n. 4, p. 967-1005, 2009.

TIBURCIO, Carmen. Imunidade de jurisdição: o Estado federal e os Estados-membros. In: TIBURCIO, Carmen. Temas de Direito Internacional. Rio de Janeiro: Renovar, 2006. 
TRUMAN, Edwin M. Sovereign Wealth Funds: The need for greater transparency and accountability. Policy Brief. Peterson Institute for International Economics, Washington, PF07-6, p. 1-9, 2007.

ZILINSKY, Jan. Understanding sovereign wealth funds. [Working paper]. Massachusetts Institute of Technology. Disponível em: <http://web.mit.edu/zilinsky/www/Data/thesis_zilinsky.pdf>. Acesso em: 17 jul. 2012.

\section{Ely Caetano Xavier Junior}

Universidade do Estado do Rio de Janeiro Faculdade de Direito Rua São Francisco Xavier, 524 - $7^{\circ}$ andar sala 7025 - bloco A

Maracanã - 20550-900 Rio de Janeiro - RJ - Brasil exavierlauerj.br
Professor de Direito Internacional Privado NA UnIVERSIDADE DO ESTADO dO RIO DE JANEIRO

Mestre EM DiREITO INTERnACIONAL PELA UnIVERSIDADE DO ESTADO DO RIO DE JANEIRO E PELA UNIVERSIDADE DE LONDRES 
